A C T A C H E M C A S C A N D I N A V I C A $24 \quad(1970) \quad 561-568$

\title{
Electrolytic Cleavage of $\beta$-Ketosulfones
}

\author{
A Convenient Ketone Synthesis*
}

B O LAMM and BENNY SAMUELSSON

Chemical Research Laboratory, AB Hässle, Fack, S-402 20 Göteborg 5, Sweden

\begin{abstract}
The electrolytic reductive cleavage of a number of $\beta$-ketosulfones has been studied at a mercury cathode in slightly alkaline aqueous dimethylformamide. The cleavage of a $\beta$-ketosulfone and the subsequent reaction with water produces a ketone and a sulfinate ion. Since the latter fragment may be oxidized to a sulfonate ion at the anode and thus serve as depolarizer, it has been possible to use an undivided cell in the electrolysis, which represents a considerable advantage from a practical point of view.

The cationic part of the supporting electrolyte has been found to have a strong influence upon the product distribution, considerable dimerization yielding $\gamma$-diketones being observed with tetrabutylammonium ion, contrasting the behavior with lithium ion.
\end{abstract}

Tt has been stated by several authors ${ }^{1-7}$ that $\beta$-ketosulfoxides and $\beta$-keto-

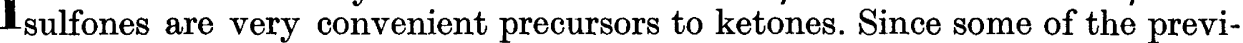
ously reported methods for the reductive cleavage of these sulfur compounds have turned out to be rather impractical on a large scale, electrolytic cleavage was attempted.

In a previous communication, ${ }^{8}$ we reported a method for the synthesis of methyl ketones by electrolytic reductive cleavage of $\beta$-ketosulfoxides. An extension of this work to include $\beta$-ketosulfones will now be described. The latter type of compounds gives superior yields upon electrolysis and is more stable than the $\beta$-ketosulfoxides.

The cathodic cleavage of carbon-sulfur bonds in simple sulfones has been described by Horner and Neumann, ${ }^{9}$ and by Manoušek, Exner and Zuman. ${ }^{10}$ Our present results, therefore, are not unexpected. In this connection, the work by Lund ${ }^{11}$ on the electroreduction of $\omega$-substituted acetophenones should also be mentioned. A sulfur-containing compound of this type, phenacyl phenyl thioether, was found to yield thiophenol and acetophenone at a mercury cathode, indicating cleavage of the bond between sulfur and the methylene group.

* Material presented at "Svenska Kemistsamfundets Organikerdagar" in Uppsala 1969.

Acta Chem. Scand. 24 (1970) No. 2 
In the electrolytic cleavage of $\beta$-ketosulfoxides previously reported, ${ }^{8} 4$ Faradays/mole of current were required since the sulfur-containing species first formed, probably a sulfenate anion, was further reduced to the thiol state. With a $\beta$-ketosulfone, the corresponding first fragment is a sulfinate anion, which is not further reduced at the potential necessary for initial bond breaking. This represents a better current economy since only $2 \mathrm{~F} / \mathrm{mole}$ are now required.

A very significant improvement of the synthetic method was the discovery that the electrolysis of $\beta$-ketosulfones could be carried out in an undivided cell. The sulfinate ions formed at the cathode served as depolarizers at the anode where they became oxidized to sulfonate ions.

It was found that optimum yields of ketone were obtained in a slightly alkaline medium. The $\mathrm{pH}$ value was kept constant with the aid of a potentiometric titrator. The problem of measuring the $\mathrm{pH}$ value potentiometrically in a current-carrying electrolyte was circumvented by pumping the electrolyte into a separate vessel in which the titration was performed.

\section{RESULTS AND DISCUSSION}

The yields of ketones upon electrolytic reduction of a number of $\beta$-ketosulfones under optimum conditions are presented in Table 1 . With some of the compounds appreciable amounts of a by-product, identified as a dimer of one of the initially formed fragments, were also obtained. The relative amounts of this dimer are also presented in Table 1.

A reasonable mechanism for the electrolytic cleavage of the $\beta$-ketosulfones, which is in accordance with the experimental observations, is presented in Fig. 1.

Table 1. Cleavage potential and product distribution in constant potential electrolysis of some $\beta$-ketosulfones.

\begin{tabular}{|c|c|c|c|c|}
\hline & Compound & Potential $^{a}$ & $\%$ Ketone $^{b}$ & $\%$ Dimer $^{c}$ \\
\hline I & $\mathrm{C}_{6} \mathrm{H}_{5} \mathrm{COCH}_{2} \mathrm{SO}_{2} \mathrm{CH}_{3}$ & -1.50 & 57 & 20 \\
\hline II & $p-\mathrm{CH}_{3} \mathrm{OC}_{6} \mathrm{H}_{4} \mathrm{COCH}_{2} \mathrm{SO}_{2} \mathrm{CH}_{3}$ & -1.50 & 57 & 20 \\
\hline III & $\mathrm{C}_{6} \mathrm{H}_{5} \mathrm{COCH}_{2} \mathrm{SO}_{2} \mathrm{C}\left(\mathrm{CH}_{3}\right)_{3}$ & -1.50 & 71 & 15 \\
\hline IV & $p-\mathrm{CH}_{3} \mathrm{OC}_{6} \mathrm{H}_{4} \mathrm{COCH}_{2} \mathrm{SO}_{2} \mathrm{C}_{6} \mathrm{H}_{5}$ & -1.50 & 92 & 0 \\
\hline $\mathrm{V}$ & $\mathrm{C}_{6} \mathrm{H}_{5} \mathrm{COCHSO}_{2} \mathrm{C}_{6} \mathrm{H}_{5}$ & -1.50 & & 0 \\
\hline & $\mathrm{CH}_{3}$ & & & \\
\hline $\begin{array}{l}\text { VI } \\
\text { VII }\end{array}$ & $\mathrm{C}_{6} \mathrm{H}_{5} \mathrm{COCH}_{2} \mathrm{SO}_{2} \mathrm{C}_{6} \mathrm{H}_{4} \mathrm{SO}_{2} \mathrm{CH}_{3}-p$ & -1.50 & 75 & 8 \\
\hline $\begin{array}{l}\text { VII } \\
\text { VIII }\end{array}$ & $\mathrm{CH}_{3}\left(\mathrm{CH}_{2}\right)_{5} \mathrm{COCH}_{2} \mathrm{SO}_{2} \mathrm{C}_{8} \mathrm{H}_{5}$ & -1.75 & 87 & $\mathbf{0}$ \\
\hline VIII & $\mathrm{C}_{6} \mathrm{H}_{5} \mathrm{CH}_{2} \mathrm{COCH}_{2} \mathrm{SO}_{2} \mathrm{C}_{6} \mathrm{H}_{5}$ & -1.65 & 88 & 0 \\
\hline
\end{tabular}

Acta Chem. Scand. 24 (1970) No. 2 


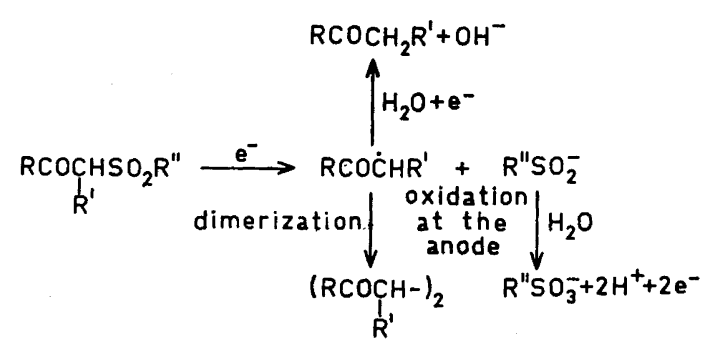

Fig. 1. Scheme for cathodic cleavage of $\beta$-ketosulfones.

Evidence for this stepwise electron transfer is the appearance of the dimer in a number of cases. The influence of structural variations in $R, R^{\prime}$, and $R^{\prime \prime}$ on the relative amount of this dimer is an interesting problem which has, however, not yet been sufficiently investigated.

As seen in Table 1, the group $\mathrm{R}^{\prime \prime}$ has been varied. The amount of data is insufficient at present to determine whether the influence of $R^{\prime \prime}$ on the product distribution is steric and/or electromeric in origin. It is sufficient to mention that when $R^{\prime \prime}$ is a phenyl group, the dimerization is negligible under suitable conditions. It is possible with $\mathrm{R}^{\prime \prime}=$ phenyl that the $\pi$ electrons cause a planeparallel orientation of this ring to the mercury cathode surface leading to the attainment of optimum conformation in the transition state.

Some of the variations in the experimental conditions which have been attempted will now be discussed. As the supporting electrolyte, a lithium salt (the $p$-toluenesulfinate) was found to give the highest yields of ketones. In contrast, the tetrabutylammonium salt gave a poor yield of ketone $(20 \%$ with compound II, Table 1).

In the conversion of the radical first formed upon reduction to a ketone (see Fig. 1), the addition of one proton and one additional electron is required. It is an open question whether the protonation or the electron transfer occurs first. Since the formation of a carbanion from a radical via electron transfer cannot take place reversibly at the working cathode, prior protonation seems more consistent with the experimental observations that the nature of the supporting electrolyte cation influences the product distribution. The availability of water at the cathode should be greater with the highly solvated. lithium ion than with the quaternary ammonium ion.

Other authors have applied these arguments concerning solvation differences to an entirely different reaction, namely, the Baizer hydrodimerization ${ }^{12,13}$ of acrylonitrile. In this process, a quantitative yield of dimer, adiponitrile, is obtained with tetraethylammonium $p$-toluenesulfonate as the supporting electrolyte. The use of lithium $p$-toluenesulfonate decreases the yield of adiponitrile to about $20 \%$, the main product being propionitrile formed by protonation of the dianion $\overline{\mathrm{C}} \mathrm{H}_{2} \overline{\mathrm{C}} \mathrm{HCN}$.

Another experimental parameter that can be varied is the nature of the cathode. According to Allen, ${ }^{14}$ the hydrogen overvoltage of the metal is of considerable importance for the degree of dimerization. The arguments are 
based on work of Eyring and co-workers, ${ }^{15}$ who have shown that a metal with high hydrogen overvoltage forms a weak metal-hydrogen bond. Allen ${ }^{14}$ interprets this to mean that at such a metal cathode, the molecule is attached for such a short time that only one electron is transferred. The radical thus formed can then dimerize. On the contrary, a metal with low hydrogen overvoltage forms a strong metal-hydrogen bond causing a two-electron transfer and protonation to the monomer. Since mercury is considered to form a weak metal-hydrogen bond and thereby favor dimerization, some other metals were used as the cathode material on the expectation that the dimerization would be completely suppressed. Copper and lead were chosen, both of which have lower hydrogen overvoltage than mercury. Hydrogen evolution was found to occur with both these metals at potentials necessary for cleavage at a reasonable rate, however, and Allen's hypothesis could therefore not be tested.

It was stated in the introduction that the $\mathrm{pH}$ value was kept constant during the electrolyses. In the work with $\beta$-ketosulfoxides, ${ }^{8}$ the optimum $\mathrm{pH}$ value was 11. With $\beta$-ketosulfones, however, the best results were obtained at $\mathrm{pH}$ 7.8. These values are based on a polarographic investigation of some representative substrates in different buffer solutions using a dropping mercury electrode and on the actual results obtained in constant potential electrolysis (c.p.e.) runs. In acidic media reduction of the carbonyl function interferes with the $\mathrm{C}-\mathrm{S}$ bond cleavage, and in too basic media by-products are formed in the preparative runs, possibly due to Claisen condensation reactions.

In a membrane-separated cell, the $\mathrm{pH}$ value of the catholyte generally tends to increase during a run and in the work on $\beta$-ketosulfoxides previously reported, ${ }^{8}$ titration with mineral acid was carried out:

In a contrast, the $\mathrm{pH}$ value tended to decrease during the electrolyses of the $\beta$-ketosulfones, which were carried out in an undivided cell (two protons are formed at the anode, whereas only one is consumed at the cathode; see Fig. 1). The electrolyte was therefore titrated with lithium hydroxide.

In the electrolyses of the $\beta$-ketosulfones, lithium $p$-toluenesulfinate was used as the supporting electrolyte.

It is seen in Fig. 1 that one of the cleavage fragments is a sulfinate ion, and since, in the depolarization process, exactly one such species is consumed at the anode per molecule of substrate (when no dimer is formed), the supporting electrolyte can, at least theoretically, be present in a catalytic amount at the start of the reaction. The overall cleavage process may be considered a redox disproportionation reaction, $\mathrm{RCOCH}_{2} \mathrm{SO}_{2} \mathrm{R}^{\prime}+\mathrm{H}_{2} \mathrm{O} \rightarrow \mathrm{RCOCH}_{3}+\mathrm{R}^{\prime} \mathrm{SO}_{3} \mathrm{H}$.

With this in mind, it is not entirely unreasonable to ask why electricity must be used at all to bring about the reaction. A probable answer is that it is thermodynamically unfavored. It is pertinent to add that if $\beta$-ketosulfones are treated with strong bases, they may react in a retro-Claisen fashion to form carboxylate ions and sulfones, ${ }^{16 a}$ indicating that the base-catalyzed cleavage takes place across a different bond than does the electrolytic cleavage. 


\section{EXPERIMENTAL}

\section{Preparation of compounds}

General remarks. Melting points were determined on a Kofler Heizbank or on a Kofler Hot Stage Microscope. NMR spectra were recorded on a Varian T 60 instrument. Preparation of the sulfones used as precursors to $\beta$-ketosulfones. Dimethyl sulfone. Dimethyl sulfoxide, $75 \mathrm{~g}(0.96 \mathrm{~mole})$, was dissolved in $120 \mathrm{~g}$ of glacial acetic acid in a $500 \mathrm{ml}$ round-bottomed flask fitted with a stirrer, reflux condenser and a separatory funnel, and heated on a steam bath. $120 \mathrm{~g}(1.06 \mathrm{~mole})$ of $30 \%$ hydrogen peroxide was added dropwise with stirring at such a rate that the reflux was under control. After the addition was complete, the solution was refluxed for one hour and evaporated to dryness.

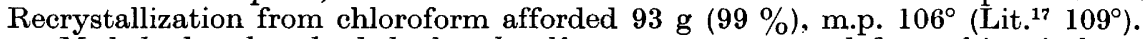

Methyl phenyl and ethyl phenyl sulfone were preparated from thioanisole and thiophenetole, respectively, by oxidation with slightly more than two equivalents of hydrogen peroxide $(30 \%)$ as described above for dimethyl sulfone. The yields were quantitative. Methyl phenyl sulfone, m.p. $88^{\circ}$ (Lit. ${ }^{17} 88^{\circ}$ ). Ethyl phenyl sulfone, m.p. $41^{\circ}$ (Lit. ${ }^{17} 42^{\circ}$ ).

Methyl t-butyl sulfone. $t$-Butyl mercaptan, $63 \mathrm{~g}(0.70 \mathrm{~mole})$, was dissolved in $200 \mathrm{ml}$ of water containing $31.5 \mathrm{~g}(0.77 \mathrm{~mole})$ of sodium hydroxide. The solution was stirred while $97 \mathrm{~g}$ ( 0.77 mole) of dimethyl sulfate was added dropwise during a 30 min period. Heat was evolved during the reaction. Stirring was maintained for an additional hour and the phases were separated. The aqueous phase was extracted once with ether. The combined organic phases were washed with a $2 \mathrm{M}$ sodium hydroxide solution followed by a saturated sodium chloride solution. Drying over anhydrous magnesium sulfate and evaporation afforded $50.2 \mathrm{~g}(69 \%)$ of crude methyl $t$-butyl sulfide. $36 \mathrm{~g}(0.35$ mole) of the sulfide was directly oxidized with slightly more than two equivalents of hydrogen peroxide as described above. In order to obtain an acceptable yield, however, the temperature was kept at $65^{\circ}$ during the oxidation. Evaporation to dryness and recrystallization from chloroform afforded $41.4 \mathrm{~g}(65 \%)$, m.p. $72^{\circ}\left(\right.$ Lit. $\left.^{17} 78-79^{\circ}\right)$.

Methyl p-nitrophenyl sulfone. Following the procedure given by Price and Stacy, ${ }^{18}$ $p$-nitrochlorobenzene was converted to $p$-nitrothiophenol in $50 \%$ yield. Alkylation with dimethyl sulfate and oxidation with a slight excess of hydrogen peroxide were carried out according to the standard methods described above. The yields of the two last steps were essentially quantitative. M.p. $141^{\circ}$ (Lit. $^{17} 142.5^{\circ}$ ).

p-Methylsulfonylthioanisole was synthesized according to Burton and $\mathrm{Hu} .^{19}$ Overall yield $42 \%$, m.p. $98^{\circ}$. (Lit. ${ }^{10} 98-99^{\circ}$ ). This compound was condensed with ethyl anisate as described below and the thiomethyl group of the resulting $\beta$-ketosulfone was oxidized to the methylsulfonyl group with hydrogen peroxide in acetic acid solution.

Preparation of $\beta$-ketosulfones. General procedure. In a multi-necked round-bottomed flask, fitted with a Hershberg stirrer, a reflux condenser and a pressure-equalizing dropping funnel, $350 \mathrm{ml}$ of toluene was placed. The apparatus was dried by distilling out $50 \mathrm{ml}$ of the toluene, which entrained the moisture. The condenser was protected by a drying tube containing silica gel, and a slow stream of dry argon was passed through the flask during the following step.

Sodium hydride $(0.4$ mole, in the form of $19.2 \mathrm{~g}$ of $50 \%$ suspension in mineral oil) was added. The mixture was again heated to reflux and a solution of 0.2 mole of sulfone in 0.2 mole of ester was added at such a rate that the reflux and hydrogen evolution were under control. The mixture was refluxed with rapid stirring until the hydrogen evolution ceased (from $0.5 \mathrm{~h}$ for dimethyl sulfone to $3 \mathrm{~h}$ for methyl phenyl sulfone). The mixture was cooled and carefully added to 11 of ice water with rapid stirring.

The two-phase mixture was stirred thoroughly and acidified with dilute hydrochloric acid to precipitate the $\beta$-ketosulfone. The three-phase system was filtrated with suction and the two liquid phases were separated. The aqueous phase was extracted with three portions of chloroform. The combined toluene and chloroform phases were dried over anhydrous magnesium sulfate and the solvents were evaporated. The mineral oil was washed away with light petroleum ether and the remaining $\beta$-ketosulfone was combined with the main crop and recrystallized from $95 \%$ ethanol. The yields and melting points of the $\beta$-ketosulfones are given in Table 2 . The NMR spectra were all in accordance with the proposed structures. 
Table 2. Yields and melting points of $\beta$-ketosulfones.

\begin{tabular}{|c|c|c|c|}
\hline Compound & $\%$ Yield & \multicolumn{2}{|c|}{ M.p. ${ }^{\circ} \mathrm{C}$} \\
\hline 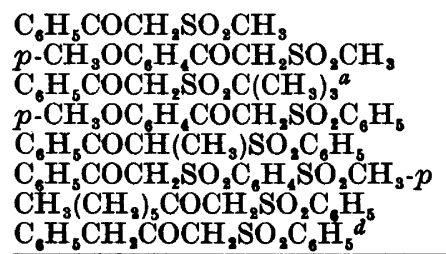 & $\begin{array}{l}94 \\
97 \\
25 \\
80 \\
84 \\
64^{c} \\
67 \\
75\end{array}$ & $\begin{array}{r}108 \\
139 \\
90 \\
114 \\
77 \\
177 \\
41 \\
89\end{array}$ & $\begin{array}{c}106-107^{20} \\
137-138^{20} \\
-{ }^{b} \\
-{ }^{b} \\
-{ }^{b} \\
-^{b} \\
-^{b}\end{array}$ \\
\hline
\end{tabular}

${ }^{a}$ Condensation carried out in dimethyl sulfoxide.

$b$ These compounds are believed to be new.

$c$ Yield for $\mathrm{C}_{6} \mathrm{H}_{5} \mathrm{COCH}_{2} \mathrm{SO}_{2} \mathrm{C}_{6} \mathrm{H}_{4} \mathrm{SCH}_{3}-p$. The oxidation yield of this substance is $99 \%$.

$d$ In order to avoid self-condensation of the ester, this was not added until the hydrogen evolution had ceased ( $3 \mathrm{~h})$.

The condensation of ethyl benzoate and methyl $t$-butyl sulfone failed in refluxing toluene, however, since the sulfone decomposes at temperatures higher than the melting point $\left(72^{\circ}\right)$. way:

For this reason, t-butylsulfonylmethyl phenyl ketone was synthesized in the following

In a $500 \mathrm{ml}$ three-necked round-bottomed flask fitted with a stirrer, a reflux condenser protected by a drying tube and a pressure-equalizing dropping funnel, 0.4 mole of methylsulfinyl carbanion was generated from 0.4 mole of sodium hydride (as $50 \%$ suspension in mineral oil) and $180 \mathrm{ml}$ of dimethyl sulfoxide (freshly distilled from calcium hydride, b.p. $64^{\circ} / 4 \mathrm{~mm}$ ) according to Corey and Chaykovsky. ${ }^{1}$ A slow stream of dry argon was passed through the flask.

When the hydrogen evolution had ceased, the mixture was cooled and $27.2 \mathrm{~g}(0.2 \mathrm{~mole})$ of methyl $t$-butyl sulfone in $100 \mathrm{ml}$ of dry tetrahydrofuran was added carefully with rapid stirring and cooling in an ice bath. $15 \mathrm{sec}$ after addition, $30 \mathrm{~g}(0.2 \mathrm{~mole})$ of ethyl benzoate was quickly added. The ice bath was then removed and the mixture was stirred at room temperature for $30 \mathrm{~min}$. The reaction mixture was poured into $1 \mathrm{l}$ of ice water and acidified with dilute hydrochloric acid. The $\beta$-ketosulfone was extracted with three $250 \mathrm{ml}$ portions of chloroform. Washing with water, drying, and evaporating the chloroform left a black oil which was dissolved in $100 \mathrm{ml}$ of $2 \mathrm{M}$ sodium hydroxide solution. The resulting solution was washed with one $50 \mathrm{ml}$ portion of chloroform. The phases were separated and the aqueous phase acidified with dilute hydrochloric acid to $\mathrm{pH} 3$. The $\beta$-ketosulfone precipitated as an oil which crystallized within one hour. Two recrystallizations from $95 \%$ ethanol afforded $12 \mathrm{~g}(25 \%)$, m.p. $90^{\circ}$.

The condensation of methyl $p$-nitrophenyl sulfone with ethyl anisate failed completely. This was not surprising since it is a known fact that $p$-nitrophenyl compounds are generally useless in Claisen condensations.

Lithium p-toluenesulfinate. Sodium $p$-toluenesulfinate ${ }^{16 \mathrm{~b}}$ was neutralized with cold dilute hydrochloric acid. The precipitated $p$-toluenesulfinic acid was filtered off and neutralized with lithium hydroxide. The aqueous solution was then evaporated to dryness.

\section{Electrolysis runs}

An apparatus schematically shown in Fig. 2 was used. The potentiostat was an Amel Model 555. The amount of current consumed was measured by integrating the voltage drop along the lead from the negative terminal of the potentiostat to the cathode. 


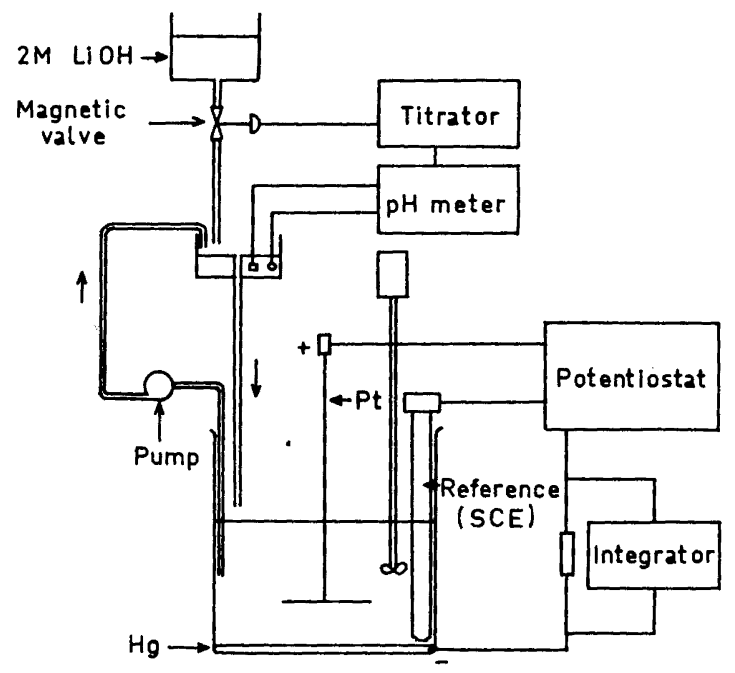

Fig. 2. Electrolysis apparatus.

The integrator was based on a Philbrick Model SP2AU operational amplifier. The potentiometric titrator was a Radiometer Model TTT 1c. The mercury cathode exposed an area of about $50 \mathrm{~cm}^{2}$. The anode was a bright platinum disk, about $15 \mathrm{~cm}^{2}$ in area, placed $1 \mathrm{~cm}$ above the cathode. The reference electrode was an ordinary saturated calomel electrode (SCE) from Radiometer.

In the electrolysis vessel (a $500 \mathrm{ml}$ beaker), $0.05 \mathrm{~mole}$ of the $\beta$-ketosulfone to be cleaved was dissolved in $200 \mathrm{ml}$ of dimethylformamide (DMF) and $20 \mathrm{ml}$ of water. $2 \mathrm{~g}$ of lithium $p$-toluenesulfinate was added. The apparatus was turned on and adjusted to the desired potential. When $2 F /$ mole of current had been introduced, the electrolysis was interrupted.* After neutralizing the electrolyte with dilute sulfuric acid, $300 \mathrm{ml}$ of water and $250 \mathrm{ml}$ of pentane were added and the mixture shaken. In the cases where a dimer formed, this precipitated and was filtered off. The phases were separated. The aqueous phase was saturated with sodium chloride and extracted with two additional $250 \mathrm{ml}$ portions of pentane. The combined organic phases were washed with water and dried over an-

Table 3. Boiling points of ketones formed in electrolysis of the corresponding $\beta$-ketosulfones.

\begin{tabular}{lccc}
\hline Compound & \multicolumn{2}{c}{$\begin{array}{c}\text { B.p. } \\
\text { Found } \\
\left({ }^{\circ} \mathrm{C} / \mathrm{mm} \mathrm{Hg}\right)\end{array}$} & $\begin{array}{c}\text { Derived from } \\
\left({ }^{\circ} \mathrm{C} / 760 \mathrm{~mm} \mathrm{Hg}\right) \\
\beta \text {-ketosulfone } \\
\text { number (Table 1) }\end{array}$ \\
\hline & $92 / 20$ & & \\
$\mathrm{C}_{6} \mathrm{H}_{5} \mathrm{COCH}_{3}$ & $82 / 0.7$ & 202 & I, III, VI \\
$p-\mathrm{CH}_{3} \mathrm{OC}_{6} \mathrm{H}_{4} \mathrm{COCH}_{3}$ & $110 / 20$ & 218 & II, IV \\
$\mathrm{C}_{6} \mathrm{H}_{5} \mathrm{COCH}_{2} \mathrm{CH}_{3}$ & $90 / 40$ & 173 & V \\
$\mathrm{CH}_{3}\left(\mathrm{CH}_{2}\right)_{5} \mathrm{COCH}_{3}$ & $107 / 20$ & 216.5 & VII \\
$\mathrm{C}_{6} \mathrm{H}_{5} \mathrm{CH}_{2} \mathrm{COCH}_{3}$ & $\mathrm{COCH}_{3}$ & & VII \\
\hline
\end{tabular}

* Note added in proof. In the cases where dimerization occurs, less than this amount of current was consumed.

Acta Chem. Scand. 24 (1970) No. 2 
hydrous magnesium sulfate, filtered and evaporated. The residue was distilled. The boiling points determined are collected in Table 3. All NMR spectra were in accordance with the proposed structures.

The dimers formed were recrystallized from $95 \%$ ethanol. The melting points are: 1,2-dibenzoyl ethane $145^{\circ}$ (Lit. $\left.{ }^{17} 144-145^{\circ}\right)$; 1,2-dianisoyl ethane $152^{\circ}\left(\right.$ Lit. $^{17} 154^{\circ}$ ). The NMR spectra were in accordance with the proposed structures. No further products could be detected.

Acknouledgement. Financial support has been provided by the Swedish Natural Science Research Council. We also wish to thank Doc. Arne Brändström and Prof. Lars Melander for valuable discussions and criticism. The linguistic correction has been carried out by Johanna Andersson B.A., whose help is much appreciated.

\section{REFERENCES}

1. Corey, E. J. and Chaykovsky, M. J. Am. Chem. Soc. 86 (1964) 1639; 87 (1965) 1344.

2. Becker, H.-D., Mikol, G. J. and Russell, G. A. J. Am. Chem. Soc. 85 (1963) 3410.

3. Russell, G. A. and Becker, H.-D. J. Am. Chem. Soc. 85 (1963) 3406.

4. Gassman, P. G. and Richmond, G. D. J. Org. Chem. 31 (1966) 2355.

5. Truce, W. E., Bannister, W. W. and Knospe, R. H. J. Org. Chem. 27 (1962) 2821.

6. Looker, J. J. J. Org. Chem. 31 (1966) 2714.

7. Truce, W. E. and Knospe, R. H. J. Am. Chem. Soc. 77 (1955) 5063.

8. Lamm, B. and Samuelsson, B. Acta Chem. Scand. 23 (1969) 691.

9. Horner, L. and Neumann, H. Chem. Ber. 98 (1965) 1715.

10. Manoušek, O., Exner, O. and Zuman, P. Collection Czechoslov. Chem. Commun. 33 (1968) 3988

11. Lund, H. Acta Chem. Scand. 14 (1960) 1927.

12. Petrovich, J. P., Anderson, J. D. and Baizer, M. M. J. Org. Chem. 31 (1966) 3897 and previous publications in this series.

13. Baizer, M. M. J. Electrochem. Soc. 111 (1964) 215.

14. Allen, M. J. Organic Electrode Processes, Chapman \& Hall, London 1958, p. 47.

15. Eyring, H., Glasstone, S. and Laidler, K. J. J. Chem. Phys. 7 (1939) 1053.

16. Houben, J. and Weyl, T. Methoden der Organischen Chemie 9, Thieme, Stuttgart 1955; a) p. 252 ; b) p. 306 .

17. Beilstein's Handbuch der Organischen Chemie.

18. Price, C. C. and Stacy, G. W. J. Am. Chem. Soc. 68 (1946) 498.

19. Burton, H. and Hu, P. F. J. Chem. Soc. 1948604.

20. Becker, H.-D. and Russell, G. A. J. Org. Chem. 28 (1963) 1896.

Received August 27, 1969. 